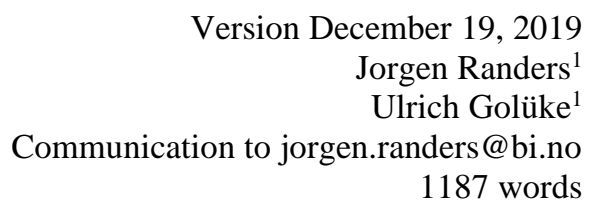

\title{
The first climate tipping point - Already in the past?
}

1 BI Norwegian Business School

Subtitle

Humanity may have passed its first climate tipping point and face self-sustained melting of the permafrost for hundreds of years even if all man-made GHG emissions are stopped.

\begin{abstract}
Our climate model (ESCIMO) indicates that the world is already past its first climate tipping point. In ESCIMO, even if man-made GHG emissions are cut to zero in 2020, the global average surface temperature keeps rising for more than a thousand years. This is because selfsustained melting of the permafrost continues - even after man-made GHG emissions have been brought to zero and the man-made $\mathrm{CO}_{2}$ in the atmosphere has been absorbed by the oceans - because of high concentrations of water vapor in the warmer atmosphere. In our Base Case scenario, where man-made emissions come to zero in 2100, by the year 2500 warming reaches $+3^{\circ} \mathrm{C}$ and the sea level +3.6 meters relative to the situation in 1850 . Luckily, self-sustained warming can be stopped through early, huge-scale, and long-lasting CCS (carbon capture and storage).
\end{abstract}

\section{Introduction}

IPCC has discussed the possibility of tipping points in the climate system for two decades. Tipping points are "points-of-no-return" - thresholds which, once surpassed, fundamentally change the dynamics of the climate system. Recently (Lenton et al, 2019) summarized the global situation and warned that tipping points may be closer in time than commonly believed.

In this commentary we want to report that our climate model (ESCIMO) indicates that humanity already has moved past the first climate tipping point. In ESCIMO current temperatures are high enough to trigger self-sustained melting of the permafrost, irrespective of how deep emissions cut humanity achieve in the future.

\section{Method}

We have developed ESCIMO (Earth System Climate Interpretable Model), which is an earth system model of low complexity consisting of approximately 50 non-linear differential equations (Randers et al, 2016). ESCIMO is a system dynamics model written in Vensim. It runs on a laptop computer in seconds and is simple enough to make it possible to understand the reasons underlying the model's behavior (its development over time) when run under various assumptions.

ESCIMO consists of three main sectors that track carbon flows, energy flows, and albedo change at the global level. The three sectors are interconnected through several feedback loops, and ESCIMO includes most of the high-level cause-and-effect interactions that are known to influence global developments in the climate area. ESCIMO was calibrated by 
using available data and theory as summarized by (IPCC, 2013). The ESCIMO Base Case simulation from 1850 up to the present gives a satisfactory replication of observed history. ESCIMO is made to test the dynamic effects of various proposed climate policies up to year 2100. In other words, to calculate the resulting time development over future decades of exogenous policy drivers. Many simulations have been made, with understandable and unsurprising results, as shown in (Randers et al, 2016).

\section{Experiment}

However, ESCIMO can be run much farther into the future, tracking the model response to exogenously given time-series for man-made GHG emissions. It takes only a few seconds to extend the Base Case scenario to the year 2500, as shown in Figure 1.

The historical part (1900-2015) of the simulation is intuitive and understandable. Rising manmade emissions of greenhouse gases (GHGs) lead to an increase in the concentration of GHG in the atmosphere, which in turn leads to an increase in the global average surface temperature. Over time the $\mathrm{CO}_{2}$ migrates from the atmosphere to the biosphere (being converted to biomass in living matter and soils) at a rate that is determined by the temperature and the amount of $\mathrm{CO}_{2}$ in the atmosphere. $\mathrm{CO}_{2}$ also moves from the atmosphere to the ocean surface, and later into the deep ocean. The warming effect of man-made GHG in the atmosphere is greatly enhanced by the increased amount of water vapor that present in a warmer atmosphere, since water is a strong greenhouse gas.

Going forwards (2015 -2100) - and using what we believe is the most likely future emissions scenario, where man-made emissions peak in the 2030s and are cut to zero by 2100 (Randers, 2012) - ESCIMO calculates a peak in the temperature at $+2.5^{\circ} \mathrm{C}$ above pre-industrial times in the 2080s. The warm atmosphere melts the world's glaciers and the Arctic sea ice, drawing heat from the atmosphere and leading to a temporary decline in the temperature when humanity reduces his emission of GHGs to zero (from the 2080s to 2150s). But the temperature remains high enough to move the southern border of the permafrost towards the north, continuously releasing methane from frozen biomass in the process.

While the developments to 2150 are understandable, developments in ESCIMO beyond 2150 are more surprising (counter-intuitive). As shown in Figure 1 after a local bottom around 2150 , the temperature once more starts rising. The surprising fact is that the rise takes place fifty years after man-made emissions have ceased, and after the concentration of $\mathrm{CO}_{2}$ in the atmosphere has been significantly reduced through absorption in the ocean.

The explanation is "self-sustained melting of the permafrost". The melting of the permafrost continuously releases methane from thawed biomass, enough to lift the concentration of methane in the atmosphere and the temperature - which in turn melts more permafrost, releasing even more methane. The methane, although short-lived (in the sense that it is converted to $\mathrm{CO}_{2}$ with a time constant of some 8 years), adds to the warming both as $\mathrm{CH}_{4}$, and as the $\mathrm{CO}_{2}$ molecules it turns into. In the current parametrization of ESCIMO, the melting of the permafrost is self-sustaining until all permafrost has been melted to all depths. This takes thousands of years - unless there is active human effort to extract greenhouse gases from the atmosphere. In the Base Case in year 2500 warming passes $+3^{\circ} \mathrm{C}$ and the sea level +3.6 meters relative to preindustrial times.

We were curious to see whether the self-sustained melting of the permafrost could be avoided by human action to cut GHG emissions earlier than in the Base Case. The answer is no. 
Figure 1 Scenario 2 shows that even if all man-made GHG emissions are (unrealistically) cut to zero in 2020 , the temperature starts rising again after 2150 - as a result of self-sustained melting of the permafrost.

\section{Discussion}

Our main discovery is that global temperature keeps rising for centuries in ESCIMO even after man-made emissions are brought to zero, and after the concentration of $\mathrm{CO}_{2}$ in the atmosphere has declined back towards the pre-industrial level through absorption in the deep ocean.

The reason is the combined warming effect of the methane released by the melting permafrost, and the high concentration of water vapor residing in the atmosphere as a consequence of the high temperatures brought about by man-made GHG emissions prior to 2100. In sum, $\mathrm{CH}_{4}$ and $\mathrm{H}_{2} \mathrm{O}$ takes over for $\mathrm{CO}_{2}$ as the main driver of continued warming.

Our experiment shows that self-sustained melting of the permafrost is triggered at much lower temperatures than formerly assumed: at around $+1^{\circ} \mathrm{C}$ in Figure 1 Scenario 2. Other ESCIMO runs (where emissions are cut contra-factually several decades before 2020) indicate that self-sustained melting is triggered at below $+0.5^{\circ} \mathrm{C}$.

Other experiments show that it is possible (in ESCIMO) to bring the temperature back down to preindustrial levels. But it requires dramatic extraordinary action: huge-scale and longlasting CCS (carbon capture and storage) and more radical direct capture of carbon.

\section{REFERENCES}

IPCC (2013). Climate Change 2013: The Physical Science Basis. Cambridge, UK and New York, USA, 1535 pp. doi: $10.1017 /$ CB09781107415324

Lenton, T. M., Rockstrøm J. et al. (2019). Climate tipping points - too risky to bet against, Nature 575 592-595, 28 November 2019

Randers J. (2012). 2052 - A Global Forecast for the Next Forty Years. Chelsea Green Publishing: White River Junction, VT. 400 pp. Available in 13 languages

Randers, J., Goluke, U., Wenst $\varnothing p$, F., Wenst $\varnothing p$, S. (2016). A user-friendly earth system model of low complexity: the ESCIMO system dynamics model of global warming towards 2100 . Earth System Dynamics, 7(4), 831-850. doi: 10.5194/esd-7-831-2016 

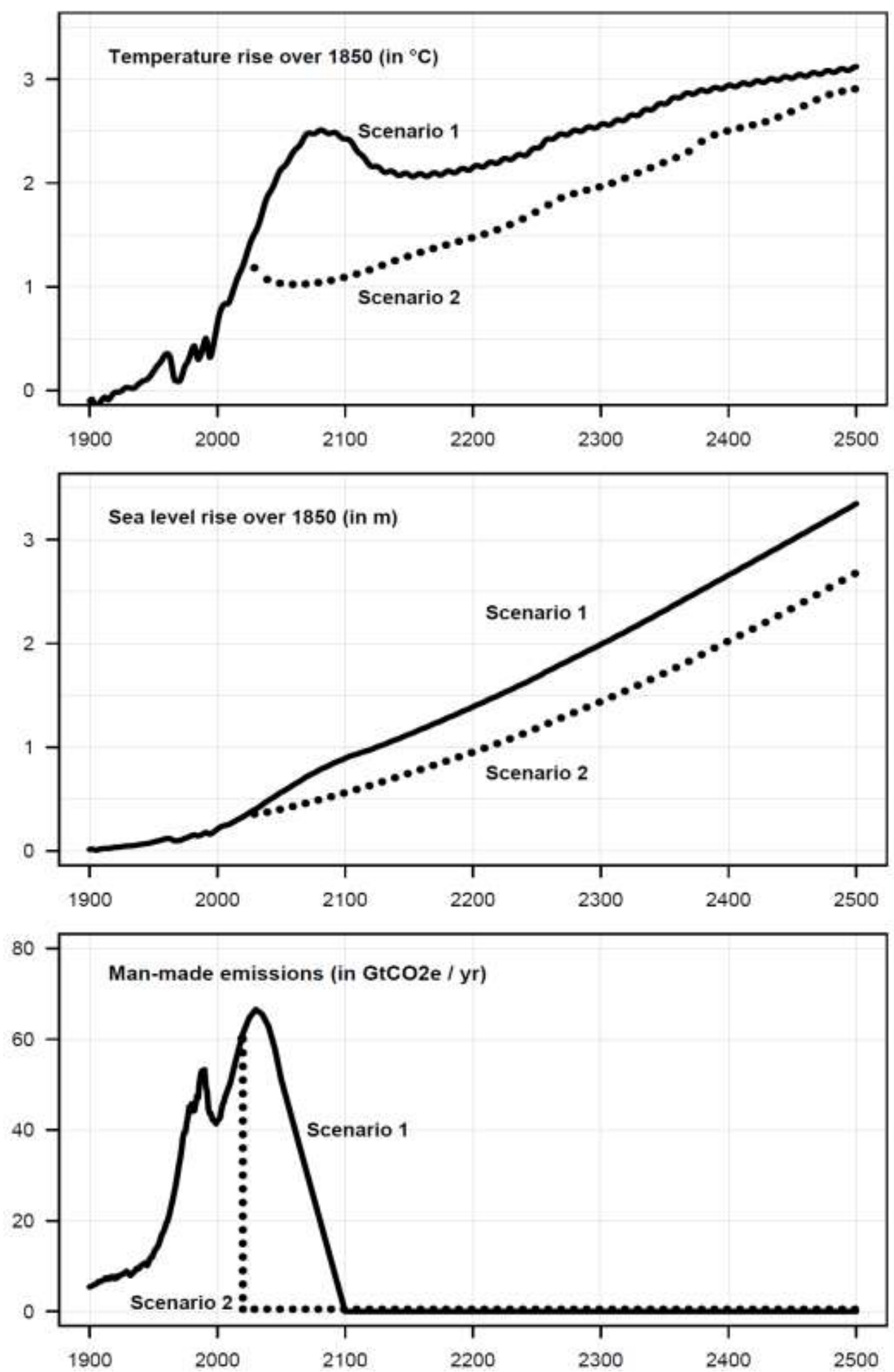

Figure 1 Man-made greenhouse gas (GHG) emissions (bottom), the global average surface temperature (GAST) (top) and sea level rise (middle) in two scenarios from 1900 to 2500. Solid black curve shows Scenario 1 - Base Case where man-made GHG emissions are phased out by 2100. Black dotted curve shows Scenario 2 - Stop in 2020 where man-made GHG emissions are cut to zero in 2020. In both cases the global temperature keeps rising in the long run due to self-sustained melting of the permafrost. 